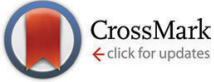

Cite this: Chem. Commun., 2017, 53, 1619

Received 7th November 2016, Accepted 9th January 2017

DOI: $10.1039 / c 6 c c 08892 a$

www.rsc.org/chemcomm

\section{Accelerated room-temperature crystallization of ultrahigh-surface-area porous anatase titania by storing photogenerated electrons $\dagger$}

\author{
Juan Su, ${ }^{a}$ Xiaoxin Zou, ${ }^{b}$ Binghan Li, ${ }^{a}$ Hui Chen, ${ }^{b}$ Xinhao Li, ${ }^{c}$ Qiuying Yu, ${ }^{c}$ Qixi Mi*a \\ and Jie-Sheng Chen*c
}

\begin{abstract}
Room-temperature crystallization, a mild and energy-efficient process, shows important application potentials for developing functional materials. We significantly accelerated the crystallization of amorphous $\mathrm{TiO}_{2}$ at room temperature by storing photogenerated electrons and the resulting porous anatase titania exhibits ultrahigh surface areas up to $736 \mathrm{~m}^{2} \mathrm{~g}^{-1}$.
\end{abstract}

In recent years, considerable research efforts have been made for the development of mild chemical synthesis routes without energy-intensive processes to meet the requirement of green chemistry (eco-friendly and energy efficient) and prospective applications. ${ }^{1,2}$ Furthermore, low- and room-temperature synthesis steps are particularly needed for the preparation of functional materials with specific structures. Compared with the energyintensive approaches, mild synthesis routes would be helpful in maintaining some compositions, morphologies or structures, and thus beneficial for related properties and functions of materials. ${ }^{2}$

Porous titania is one of the most important synthetic functional semiconductors because of its excellent physical/chemical properties and large surface area. ${ }^{3-5}$ The construction of pore channels conventionally involves a final thermal treatment at $T \geq 400{ }^{\circ} \mathrm{C}$ to remove the template/surfactants/remnants. In addition, in most cases, an energy-intensive treatment process is needed to improve their crystallinity, e.g. calcination, solvo/hydrothermal, microwave treatment, etc. (Table S1 in the ESI $\dagger$ ). Recently, we reported the spontaneous crystallization of porous amorphous $\mathrm{TiO}_{2}\left(\mathrm{Am}-\mathrm{TiO}_{2}\right)$ to anatase titania with a large surface area and excellent photocatalytic performance, at room temperature in 80 days. $^{6}$

\footnotetext{
${ }^{a}$ School of Physical Science and Technology, ShanghaiTech University,

Shanghai 201210, China. E-mail: miqx@shanghaitech.edu.cn

${ }^{b}$ State Key Laboratory of Inorganic Synthesis and Preparative Chemistry, Jilin University, Changchun 130012, China

${ }^{c}$ School of Chemistry and Chemical Engineering, Shanghai Jiao Tong University, Shanghai 200240, China. E-mail: chemcj@sjtu.edu.cn

$\dagger$ Electronic supplementary information (ESI) available: Experimental details and supporting results. See DOI: 10.1039/c6cc08892a
}

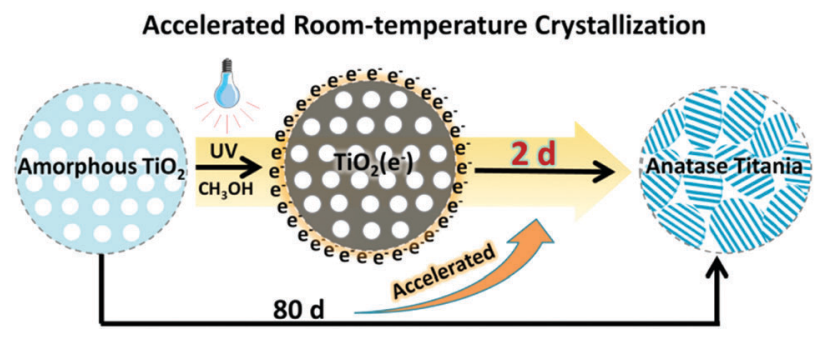

Fig. 1 Schematic representation of the accelerated room-temperature crystallization from $\mathrm{Am}-\mathrm{TiO}_{2}$ to anatase titania. Crystallization time is reduced from $80 \mathrm{~d}$ to $2 \mathrm{~d}$ by storing $\mathrm{e}^{-}$.

The development of such a room-temperature crystallization process without any solvent, additive, or catalyst is significant for exploring green and energy-efficient chemical synthesis. Nonetheless, the acceleration of the process of room-temperature crystallization is desirable for the research and application of such a mild synthetic route in the development of functional materials.

Herein, we report that the room-temperature crystallization from amorphous to anatase porous titania can be significantly accelerated by storing photogenerated electrons $\left(\mathrm{e}^{-}\right)$(Fig. 1). In most cases, $\mathrm{e}^{-}$acts as an intermediate with a limited amount and short lifetime. Recently, we have successfully stored abundant $\mathrm{e}^{-}$on the surface of porous titania in the form of $\mathrm{Ti}^{3+}$ through photochemical reduction. ${ }^{7}$ The stored $\mathrm{e}^{-}$exhibited unique applications, such as chemoselective hydrogenation of nitroarene and roomtemperature ferromagnetism. ${ }^{7-9}$ A mechanism for the accelerated room-temperature crystallization is also discussed in this work.

Porous $\mathrm{Am}-\mathrm{TiO}_{2}$ was synthesized photochemically according to our previous report. ${ }^{7}$ After $30 \mathrm{~min}$ of UV-light irradiation, abundant $\mathrm{e}^{-}$were stored on the surface of porous $\mathrm{Am}^{-\mathrm{TiO}_{2}}$ suspended in aqueous methanol (methanol as a sacrificial agent of photogenerated holes improves the accumulation of photogenerated electrons on $\mathrm{Am}^{-\mathrm{TiO}_{2}}{ }^{7}$ ). A self-made reactor with a volume of $3.5 \mathrm{~L}$ was applied to provide irradiation, constant cooling and stirring in a lightproof enclosure as shown in Fig. S1 (ESI $\dagger$ ). We can carry out the storage of $\mathrm{e}^{-}$in 
a

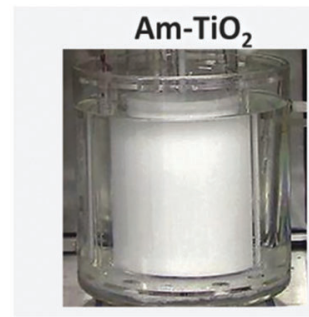

b

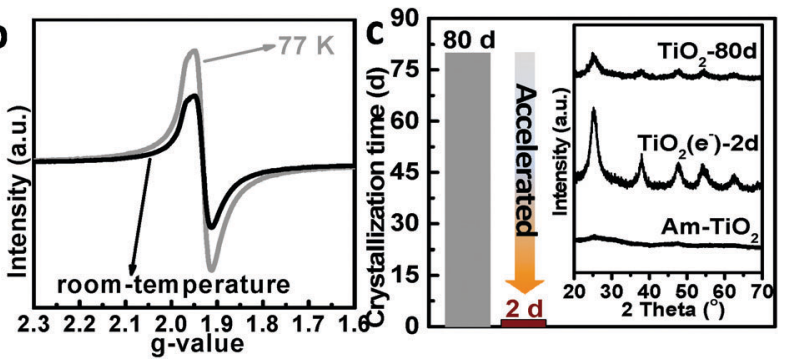

Fig. 2 (a) Photographs of $\mathrm{Am}-\mathrm{TiO}_{2}$ and $\mathrm{TiO}_{2}\left(\mathrm{e}^{-}\right)$in the photochemical reactor. (b) The electron paramagnetic resonance (EPR) spectra of $\mathrm{TiO}_{2}\left(\mathrm{e}^{-}\right)$at $77 \mathrm{~K}$ and room-temperature. (c) Crystallization time of $\mathrm{TiO}_{2}-$ 80d (grey) and $\mathrm{TiO}_{2}\left(\mathrm{e}^{-}\right)-2 \mathrm{~d}$ (red); inset: the powder X-ray diffraction (XRD) patterns of $\mathrm{Am}-\mathrm{TiO}_{2}, \mathrm{TiO}_{2}\left(\mathrm{e}^{-}\right)-2 \mathrm{~d}$, and $\mathrm{TiO}_{2}-80 \mathrm{~d}$.

at least $140 \mathrm{~g}$ titania sample each time. As $\mathrm{e}^{-}$is stored on the titania surfaces (denoted as $\mathrm{TiO}_{2}\left(\mathrm{e}^{-}\right)$), the color of the reaction mixture gradually turned from white to dark gray (Fig. 2a, Movie 1 in the ESI $\dagger$ ), indicating that $\mathrm{e}^{-}$are trapped by $\mathrm{Ti}^{4+}$ ions and then stored in the form of $\mathrm{Ti}^{3+}$ ions. A characteristic $\mathrm{Ti}^{3+}$ signal at $g=1.948$ was detected in the electron paramagnetic resonance (EPR) spectrum of $\mathrm{TiO}_{2}\left(\mathrm{e}^{-}\right)$(Fig. 2b). ${ }^{7}$ Subsequently, $\mathrm{TiO}_{2}\left(\mathrm{e}^{-}\right)$was preserved for 2,5 , and 40 days, and the washed and dried samples (surface $\mathrm{Ti}^{3+} / \mathrm{e}^{-}$were oxidized by $\mathrm{O}_{2}$ during washing and drying in air, Fig. S2 in the ESI $\dagger$ ) were denoted as $\mathrm{TiO}_{2}\left(\mathrm{e}^{-}\right)-2 \mathrm{~d}$, $\mathrm{TiO}_{2}\left(\mathrm{e}^{-}\right)-5 \mathrm{~d}$, and $\mathrm{TiO}_{2}\left(\mathrm{e}^{-}\right)-40 \mathrm{~d}$, respectively. By contrast, the samples crystallized in air at room temperature, including $\mathrm{TiO}_{2}-80 \mathrm{~d}$ and $\mathrm{TiO}_{2}-$ 300d, were also synthesized according to the previous method. ${ }^{6}$

As shown in Fig. 2c, $\mathrm{TiO}_{2}\left(\mathrm{e}^{-}\right)-2 \mathrm{~d}$ began to crystallize after 2 days, which was significantly accelerated compared with $\mathrm{TiO}_{2}$ 80d (began to crystallize after 80 days). The inset in Fig. 2c shows the powder X-ray diffraction (XRD) patterns of $\mathrm{Am}-\mathrm{TiO}_{2}$, $\mathrm{TiO}_{2}\left(\mathrm{e}^{-}\right)-2 \mathrm{~d}$ and $\mathrm{TiO}_{2}$-80d. In contrast to $\mathrm{Am}-\mathrm{TiO}_{2}$ with no observable XRD peaks, both of $\mathrm{TiO}_{2}\left(\mathrm{e}^{-}\right)-2 \mathrm{~d}$ and $\mathrm{TiO}_{2}-80 \mathrm{~d}$ show a set of characteristic peaks of anatase titania without any impurity phase after crystallization at room temperature. Although the crystallization time of $\mathrm{TiO}_{2}\left(\mathrm{e}^{-}\right)-2 \mathrm{~d}$ is one-fortieth of that of $\mathrm{TiO}_{2}-80 \mathrm{~d}$, $\mathrm{TiO}_{2}\left(\mathrm{e}^{-}\right)-2 \mathrm{~d}$ shows higher crystallinity. The high crystallinity of $\mathrm{TiO}_{2}\left(\mathrm{e}^{-}\right)-2 \mathrm{~d}$ can be further confirmed by high-resolution transmission electron microscopy (HR-TEM, Fig. S3 in the ESI $\dagger$ ) and selected-area electron diffraction (SAED) patterns (Fig. S4 in the ESI $\dagger$ ). The lattice spacing 0.35, 0.24 , and $0.19 \mathrm{~nm}$ observed by HR-TEM correspond to the (101), (004) and (200) crystal planes of anatase, respectively. The diffraction rings observed in the SAED pattern also agree with these results.

In addition, $\mathrm{N}_{2}$-adsorption measurements reveal that both of $\mathrm{TiO}_{2}\left(\mathrm{e}^{-}\right)-2 \mathrm{~d}$ and $\mathrm{TiO}_{2}-80 \mathrm{~d}$ inherit the highly porous texture
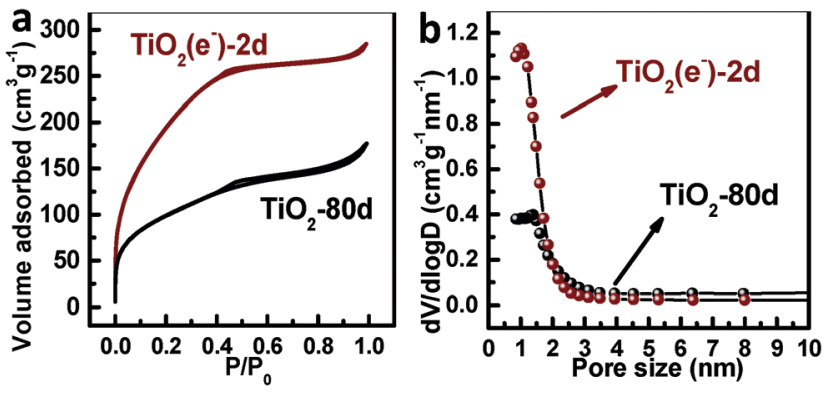

Fig. 3 (a) $\mathrm{N}_{2}$ adsorption-desorption isotherms and (b) pore size distribution of $\mathrm{TiO}_{2}\left(e^{-}\right)-2 \mathrm{~d}$ and $\mathrm{TiO}_{2}-80 \mathrm{~d}$.

from $\mathrm{Am}_{-\mathrm{TiO}}$ (Fig. 3). In particular, to our knowledge, $\mathrm{TiO}_{2}\left(\mathrm{e}^{-}\right)-2 \mathrm{~d}$ possesses the maximum surface area $\left(736 \mathrm{~m}^{2} \mathrm{~g}^{-1}\right)$ of porous anatase titania reported so far, a value nearly twice that of $\mathrm{TiO}_{2}-80 \mathrm{~d}$ $\left(400 \mathrm{~m}^{2} \mathrm{~g}^{-1}\right.$ ) (Table $\mathrm{S} 1$ in the ESI $\dagger$ ). It is known that the crystallization process tends to impart tightness and regularity to particle packing, which would increase both the number and size of pores in a material. $\mathrm{TiO}_{2}\left(\mathrm{e}^{-}\right)-2 \mathrm{~d}$ from the accelerated crystallization possesses more pores and smaller pore sizes, which result in a larger Brunauer-Emmett-Teller (BET) surface area compared with $\mathrm{TiO}_{2}$-80d. As anticipated, after a longer crystallization time than that of $\mathrm{TiO}_{2}\left(\mathrm{e}^{-}\right)-2 \mathrm{~d}$, $\mathrm{TiO}_{2}\left(\mathrm{e}^{-}\right)-5 \mathrm{~d}$ displays a slightly smaller BET surface area $\left(689 \mathrm{~m}^{2} \mathrm{~g}^{-1}\right)$ and larger pore sizes (Fig. S5 and Table S2 in the ESI $\dagger$ ). Therefore, the storage of $\mathrm{e}^{-}$during the room-temperature crystallization process of titania not only significantly reduces the reaction time, but also contributes to the ultrahigh surface area of the asobtained porous anatase.

As shown in Fig. 4a, we compared the crystallization curves of titania with and without $\mathrm{e}^{-}$based on the evolution of XRD patterns $^{10}$ (Fig. S6 and S7 in the ESI $\dagger$ ). It was revealed that the crystallinity of titania increased at distinct rates, and both of the nucleation and crystal growth rates were accelerated by the storage of $\mathrm{e}^{-}$. In our synthetic process of anatase (Fig. S8 in the $\mathrm{ESI} \dagger$ ), titanium glycolate (TG) as the precursor of $\mathrm{Am}-\mathrm{TiO}_{2}$ is constructed by infinite chains, which consist of edge-sharing $\mathrm{TiO}_{6}$ octahedra and organic ligands. ${ }^{11}$ After removing the organic ligands by UV irradiation, TG was transformed into $\mathrm{Am}^{-\mathrm{TiO}_{2}}$, which consists of randomly arranged $\mathrm{TiO}_{6}$ octahedra

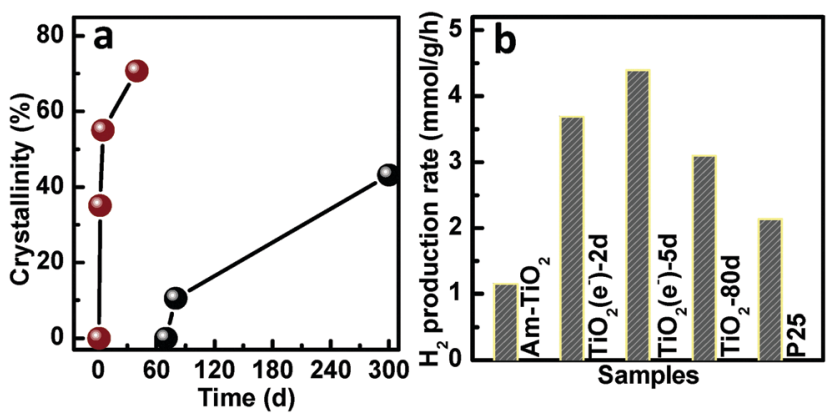

Fig. 4 (a) Room-temperature crystallization curves of titania with (red) and without (black) $\mathrm{e}^{-}$. (b) Comparison of $\mathrm{H}_{2}$ production rates. Reaction conditions: 50 mg catalyst; 1 wt\% Pt loading; aqueous methanol solution (50 vol\%, $100 \mathrm{~mL}$ ); and $300 \mathrm{~W}$ Xe lamp as a light source. 
or their edge-shared fragments (Fig. S9 in the ESI $\dagger$ ). ${ }^{6}$ An orderly rearrangement and connection of octahedral $\mathrm{TiO}_{6}$ units would produce anatase titania (containing ordered edge/corner-sharing $\mathrm{TiO}_{6}$ octahedra). Infrared spectroscopy (Fig. S10 in the ESI $\dagger$ ), thermogravimetric analysis (Fig. S11 in the ESI $\dagger$ ), and elemental analysis (Table $\mathrm{S} 3$ in the ESI $\dagger$ ) suggested that $\mathrm{Am}^{-} \mathrm{TiO}_{2}, \mathrm{TiO}_{2}\left(\mathrm{e}^{-}\right)-2 \mathrm{~d}$ and $\mathrm{TiO}_{2}\left(\mathrm{e}^{-}\right)-5 \mathrm{~d}$ contained ethylene glycol, ${ }^{12}$ which gradually decreased as the crystallization time increased from $\mathrm{Am}^{-\mathrm{TiO}_{2}}$ to $\mathrm{TiO}_{2}\left(\mathrm{e}^{-}\right)-2 \mathrm{~d}$, and then to $\mathrm{TiO}_{2}\left(\mathrm{e}^{-}\right)-5 \mathrm{~d}$. The residual ethylene glycol remaining after the TG transformation may hinder the rearrangement and interconnection of the $\mathrm{TiO}_{6}$ octahedra in $\mathrm{Am}^{-\mathrm{TiO}_{2}}$. Therefore, we propose that the storage of $\mathrm{e}^{-}$facilitates the removal of residual ethylene glycol from $\mathrm{TiO}_{6}$ octahedra and thus accelerates the room-temperature crystallization of porous titania. This is because the storage of $\mathrm{e}^{-}$turns some $\mathrm{Ti}^{4+}$ sites into $\mathrm{Ti}^{3+}$, and weakens the Ti-O bond between titania and ethylene glycol (Fig. S8, I, in the ESI + ). In addition, we demonstrated that a proton was attached to the surface oxygen combined with an $\mathrm{e}^{-}$stored on the neighboring $\mathrm{Ti}^{3+}$, , which is consistent with the concept "proton-coupled electron transfer (PCET)" proposed by Schrauben et $a .^{13}$ These protonated surfaces would be easily combined with the hydroxyl group of other $\mathrm{TiO}_{6}$ octahedra in the vicinity. ${ }^{14}$ Thus, after eliminating a $\mathrm{H}_{2} \mathrm{O}$ molecule, a bridging oxygen bond (Ti-O-Ti) would form between two neighbouring $\mathrm{TiO}_{6}$ octahedra, which favors the connection of $\mathrm{TiO}_{6}$ octahedra to form anatase (Fig. S8, II, in the ESI $\dagger$ ). In addition, we flew oxygen through $\mathrm{TiO}_{2}\left(\mathrm{e}^{-}\right)$and the resulting sample without $\mathrm{e}^{-}$could not crystallize in the same solvent system even after 40 days. This observation confirmed the key role of $\mathrm{e}^{-}$rather than the solvent in accelerating the room-temperature crystallization process.

It was previously demonstrated that $\mathrm{TiO}_{2}-80 \mathrm{~d}$ was an efficient photocatalyst for $\mathrm{H}_{2}$ evolution under UV light, due to its large surface area and anatase structure. ${ }^{6}$ Photocatalytic $\mathrm{H}_{2}$ production performance of the samples synthesized via accelerated roomtemperature crystallization was also investigated (see the ESI $\dagger$ for details). In a control experiment, there was no $\mathrm{H}_{2}$ detected in the absence of the photocatalyst or light. It should be noted that $\mathrm{e}^{-}$was not stored in the catalyst during photocatalysis, but rapidly transferred to the loaded Pt co-catalyst and then reacted with $\mathrm{H}_{2} \mathrm{O}$. Fig. 4b presents the comparison of photocatalytic $\mathrm{H}_{2}$ evolution rates of $\mathrm{Am}^{-} \mathrm{TiO}_{2}, \mathrm{TiO}_{2}-80 \mathrm{~d}, \mathrm{TiO}_{2}\left(\mathrm{e}^{-}\right)-2 \mathrm{~d}, \mathrm{TiO}_{2}\left(\mathrm{e}^{-}\right)-5 \mathrm{~d}$ and $\mathrm{P} 25$ (a benchmark photocatalyst). $\mathrm{TiO}_{2}-80 \mathrm{~d}, \mathrm{TiO}_{2}\left(\mathrm{e}^{-}\right)-2 \mathrm{~d}$, and $\mathrm{TiO}_{2}\left(\mathrm{e}^{-}\right)-$ $5 \mathrm{~d}$ show higher $\mathrm{H}_{2}$ evolution rates than those of $\mathrm{P} 25$ and $\mathrm{Am}^{-\mathrm{TiO}_{2}}$, due to their larger surface areas and anatase structure resulting from the mild room-temperature crystallization process. Compared with $\mathrm{TiO}_{2}-80 \mathrm{~d}, \mathrm{TiO}_{2}\left(\mathrm{e}^{-}\right)-2 \mathrm{~d}$ and $\mathrm{TiO}_{2}\left(\mathrm{e}^{-}\right)-5 \mathrm{~d}$ exhibited enhanced photocatalytic activities and higher photogenerated charge separation efficiency (Fig. S12 in the ESI $\dagger$ ). There was no obvious difference of absorption onset or band gap among $\mathrm{TiO}_{2}-80 \mathrm{~d}$, $\mathrm{TiO}_{2}\left(\mathrm{e}^{-}\right)-2 \mathrm{~d}$ and $\mathrm{TiO}_{2}\left(\mathrm{e}^{-}\right)-5 \mathrm{~d}$ (Fig. S13 in the ESI $\left.\dagger\right)$. The enhanced photocatalytic performance should be mainly attributed to their much larger surface area and higher crystallinity. $\mathrm{TiO}_{2}\left(\mathrm{e}^{-}\right)-5 \mathrm{~d}$ was proved to be the sample with the highest photogenerated charge separation efficiency and photocatalytic activity. This is mainly due to its high crystallinity, although its BET surface area is somewhat smaller than that of $\mathrm{TiO}_{2}\left(\mathrm{e}^{-}\right)-2 \mathrm{~d}$. In addition, 10 cycles of photocatalytic $\mathrm{H}_{2}$ evolution were performed over $\mathrm{TiO}_{2}\left(\mathrm{e}^{-}\right)-2 \mathrm{~d}$, and excellent stability was observed with no obvious loss of catalytic activity (Fig. S14 in the ESI $\dagger$ ) and no change in the crystal structure (Fig. S15 in the ESI $\dagger$ ).

In this work, a technology for storing photogenerated electrons is for the first time applied for accelerating the amorphous-anatase phase transition of porous titania materials with large surface areas at room temperature. Thanks to the storage of $\mathrm{e}^{-}$, the reaction time of such a mild room-temperature crystallization process was drastically reduced from 80 to 2 days. The as-prepared porous anatase titania materials possess ultrahigh surface areas (up to $736 \mathrm{~m}^{2} \mathrm{~g}^{-1}$ ) and high photocatalytic activity. Such a facile process permits easy scale-up and is promising for wide applications in both fundamental research and industrial productions.

This work was financially supported by the National Natural Science Foundation of China (21403140 and 21403141). We thank Dechun Qiu and Yi Zhang for their support to this work.

\section{Notes and references}

1 F. Cheng, J. Shen, B. Peng, Y. Pan, Z. Tao and J. Chen, Nat. Chem., 2011, 3, 79; J. Cravillon, S. Münzer, S.-J. Lohmeier, A. Feldhoff, K. Huber and M. Wiebcke, Chem. Mater., 2009, 21, 1410; Y. Zhou and M. Antonietti, J. Am. Chem. Soc., 2003, 125, 14960.

2 D. Zhang, T. Yoshida, T. Oekermann, K. Furuta and H. Minoura, Adv. Funct. Mater., 2006, 16, 1228; X. Liu, Y. Luo, H. Li, Y. Fan, Z. Yu, Y. Lin, L. Chen and Q. Meng, Chem. Commun., 2007, 2847; S. Ren, M. J. Bojdys, R. Dawson, A. Laybourn, Y. Z. Khimyak, D. J. Adams and A. I. Cooper, Adv. Mater., 2012, 24, 2357; S. H. Sun, D. Q. Yang, D. Villers, G. X. Zhang, E. Sacher and J. P. Dodelet, Adv. Mater., 2008, 20, 571.

3 W. Li, Z. Wu, J. Wang, A. A. Elzatahry and D. Zhao, Chem. Mater., 2014, 26, 287; A. A. Ismail, D. W. Bahnemann, L. Robben, V. Yarovyi and M. Wark, Chem. Mater., 2010, 22, 108; T. Brezesinski, J. Wang, J. Polleux, B. Dunn and S. H. Tolbert, J. Am. Chem. Soc., 2009, 131, 1802; J. Zhao, P. Xu, Y. Li, J. Wu, J. Xue, Q. Zhu, X. Lu and W. Ni, Nanoscale, 2016, 8, 5417.

4 J. Su, X.-X. Zou, Y.-C. Zou, G.-D. Li, P.-P. Wang and J.-S. Chen, Inorg. Chem., 2013, 52, 5924.

5 G. J. A. A. Soler-Illia, C. Sanchez, B. Lebean and J. Patarin, Chem. Rev., 2002, 102, 4093; W. Y. Dong, Y. J. Sun, C. W. Lee, W. M. Hua, X. C. Lu, Y. F. Shi, S. C. Zhang, J. M. Chen and D. Y. Zhao, J. Am. Chem. Soc., 2007, 129, 13894; D. L. Li, H. S. Zhou and I. Honma, Nat. Mater., 2004, 3, 65; S. Y. Choi, M. Mamak, N. Coombs, N. Chopra and G. A. Ozin, Adv. Funct. Mater., 2004, 14, 335.

6 J. Su, X. Zou, G.-D. Li, Y.-M. Jiang, Y. Cao, J. Zhao and J.-S. Chen, Chem. Commun., 2013, 49, 8217.

7 X. X. Zou, G. D. Li, K. X. Wang, L. Li, J. Su and J. S. Chen, Chem. Commun., 2010, 46, 2112; J. Su, X.-X. Zou, G.-D. Li, L. Li, J. Zhao and J.-S. Chen, Chem. Commun., 2012, 48, 9032.

8 X. X. Zou, G. D. Li, Y. N. Wang, J. Zhao, C. Yan, M. Y. Guo, L. Li and J. S. Chen, Chem. Commun., 2011, 47, 1066.

9 J. Su, X. Zou and J.-S. Chen, RSC Adv., 2014, 4, 13979.

10 G. Feng, P. Cheng, W. Yan, M. Boronat, X. Li, J.-H. Su, J. Wang, Y. Li, A. Corma, R. Xu and J. Yu, Science, 2016, 351, 1188.

11 X. X. Zou, G. D. Li, M. Y. Guo, X. H. Li, D. P. Liu, J. Su and J. S. Chen, Chem. - Eur. J., 2008, 14, 11123; D. Wang, R. Yu, N. Kumada and N. Kinomura, Chem. Mater., 1999, 11, 2008.

12 P. Liu, Y. Zhao, R. Qin, S. Mo, G. Chen, L. Gu, D. M. Chevrier, P. Zhang, Q. Guo, D. Zang, B. Wu, G. Fu and N. Zheng, Science, 2016, $352,797$.

13 J. N. Schrauben, R. Hayoun, C. N. Valdez, M. Braten, L. Fridley and J. M. Mayer, Science, 2012, 336, 1298.

14 H. Yin, Y. Wada, T. Kitamura, S. Kambe, S. Murasawa, H. Mori, T. Sakatac and S. Yanagida, J. Mater. Chem., 2001, 11, 1694. 